\title{
ESTRATÉGIAS DE PRODUÇÃO NA INDÚSTRIA DE EQUIPAMENTOS MÉDICOS DE DIAGNÓSTICO POR IMAGEM: UMA ANÁLISE DA RESSONÂNCIA MAGNÉTICA
}

\section{PRODUCTIVE STRATEGIES IN THE MEDICAL IMAGE DEVICES INDUSTRY: AN ANALYSIS OF MAGNETIC RESONANCE}

\author{
Leila C. N. Gomes \\ Doutora em Engenharia de Produção \\ Pontifícia Universidade Católica do Rio de Janeiro \\ Departamento de Engenharia Industrial \\ Rua Marquês de São Vicente, 225 Rio de Janeiro Brasil \\ foccus@openlink.com.br \\ Paulo R. T. Dalcol \\ Professor Associado \\ Pontifícia Universidade Católica do Rio de Janeiro \\ Departamento de Engenharia Industrial \\ Rua Marquês de São Vicente, 225 Rio de Janeiro Brasil \\ prtd@rdc.puc-rio.br
}

\begin{abstract}
RESUMO
Nas últimas décadas, vem ocorrendo uma importante revolução na área da tecnologia médica, em particular nos equipamentos de diagnóstico por imagem. O presente artigo concentra-se na análise e compreensão das estratégias empregadas na produção desses equipamentos, com enfoque específico na produção de equipamentos de Ressonância Magnética, pela importância de se dispor de dados e informações principalmente em países como o Brasil que, apesar de ainda não apresentarem produção nacional, fazem uso de toda essa tecnologia e necessitam preparar recursos humanos não só para a sua própria utilização, mas também para o desenvolvimento e produção de componentes e periféricos específicos. Além disso, é importante que se discuta a melhor estratégia produtiva a ser aplicada nesses países para


implantar uma indústria nacional. A metodologia empregada no estudo que deu origem ao artigo, envolve dois estudos de casos realizados em empresas produtoras de equipamentos de imagem - Philips Medical Systems (Holanda) e Siemens Medical (Alemanha). Foi possível identificar estratégias produtivas opostas aplicadas nessas empresas, analisando-se suas características gerais, vantagens e desvantagens.

Palavras-chave: Estratégia de produção, integração vertical, desverticalização, ressonância magnética, equipamentos de diagnóstico por imagem.

\begin{abstract}
In the last decades, an important revolution has taken place in the medical technology field, particularly in image diagnosis equipment. The central purpose of the present paper is to analyze and understand the strategies and productive systems used in the production of such equipment, with specific focus on the production of Magnetic Resonance equipment. It is important to make data and information available especially in countries like Brazil, which, despite still not having a national production, make use of this technology and need to prepare human resources not only for its own use but also for the development and production of specific components. Other important issue is to know which strategy is the best for these countries since some companies can intend to install their factories of image devices there. The methodology used in the present study involves case studies performed in two major manufacturers of image diagnosis equipment - Philips Medical Systems and Siemens Medical. It was possible to identify different productive strategies in these firms, and the positive and negative aspects were analyzed.
\end{abstract}

Keywords: Productive strategies, vertical integration, magnetic resonance, medical imaging devices.

\title{
1. INTRODUÇÃO
}

Nas últimas décadas, tem-se vivenciado e testemunhado uma nova revolução na área de diagnóstico por imagem. O advento da ultra-sonografia, da tomografia computadorizada, da medicina nuclear, da radiologia intervencionista e da ressonância magnética ampliou e Revista Produção Online, Florianópolis, v.7, n.7,p.16, dez./abr., 2007 
modificou de forma significativa o diagnóstico médico por imagem. A ampla aplicação dos novos métodos de imagem nas diversas áreas do conhecimento médico tornou necessária a divulgação de conhecimentos e informações, alcançando-se, desta forma, uma grande qualificação dos radiologistas.

Os benefícios obtidos com a oferta de diagnóstico por imagem de qualidade, para o tratamento de pacientes e detecção de doenças, são sentidos por toda comunidade médica e representam uma grande melhoria no atendimento e tratamento ao paciente, fazendo com que um bem estruturado serviço de diagnóstico por imagem seja o cartão de visita mais visível em um significativo número de instituições médicas.

\subsection{Equipamentos de Diagnóstico por Imagem}

Os equipamentos de diagnóstico por imagem podem ser compreendidos como aqueles utilizados por clínicos para a visualização interna do corpo humano sem intervenção ou procedimento interno, ou seja, sem a utilização de métodos invasivos. Deve-se compreender que os equipamentos de imagem, apesar de não fazerem uso de métodos totalmente invasivos podem, em alguns casos, utilizar contrastes para melhor visualização e identificação de patologias. Tais equipamentos são altamente diferenciados em várias dimensões. As diferentes tecnologias classificadas nesse segmento podem ser identificadas com os equipamentos de raio-x convencional, imagem nuclear, ultra-sonografia, radiografia digital, tomografia computadorizada e ressonância magnética (Pleatsikas \& Teece, 2001).

Dentre os tipos apresentados, um será especificamente abordado neste artigo - os equipamentos que compõem o grupo de equipamentos de ressonância magnética, tendo sido esta escolha motivada por três elementos principais:

i. Pela complexidade de seus equipamentos os quais permitem diagnósticos mais precisos de órgãos do corpo humano anteriormente obtidos apenas por métodos que apresentavam grande risco aos pacientes;

ii. Pela evolução e crescimento no uso apresentados pelos equipamentos pertencentes a este segmento nos últimos anos e

iii. Pela interdisciplinaridade identificada de conhecimentos que estão envolvidos no desenvolvimento e na produção destes equipamentos.

\subsection{Ressonância Magnética (RM)}


A Ressonância Magnética (RM), primeiramente investigada por Bloch e seus colaboradores em 1946, em Stanford e em seguida por Purcell, em Harvard, é um dos maiores avanços da medicina em matéria de diagnóstico por imagem neste século. Seus princípios são bastante complexos e envolvem conhecimentos nas mais diversas áreas das ciências exatas.

A RM é uma tecnologia de diagnósticos por imagem que utiliza um potente magneto e ondas de rádio-freqüência para produzir fotos ou imagens de estruturas e órgãos internos. Justamente por permitir que o médico observe o interior do corpo de qualquer ângulo de visão e com muito mais clareza, esta tecnologia fornece uma grande quantidade de informações obtidas mais rapidamente e, em muitos casos, de maneira mais econômica do que os antigos exames e cirurgias exploratórias (GE Sistemas Médicos, 2003).

Há inúmeras técnicas de RM, de modo que é possível individualizá-las de acordo com o problema a ser investigado. A RM oferece um poder de resolução às vezes muito superior ao da Tomografia Computadorizada. Seus exames constituem um excelente método de estudo do cérebro, medula espinhal, ossos esponjosos, pelve masculina ou feminina e grandes articulações.

As grandes vantagens da RM residem na sua segurança, uma vez que não utiliza radiação ionizante nas diversas possibilidades em promover cortes tomográficos em muitos e diferentes planos, dando uma visão panorâmica da área do corpo de interesse e, finalmente, na capacidade de mostrar características dos diferentes tecidos do corpo, conforme exemplos apresentados na Figura 1.

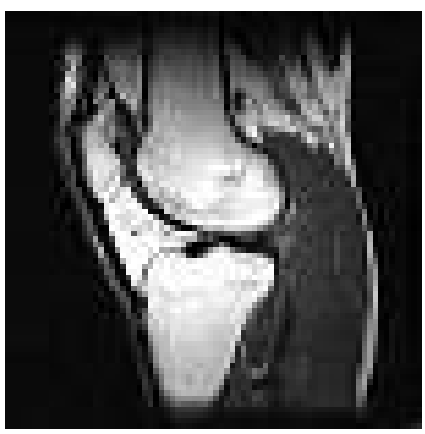

(a) joelho

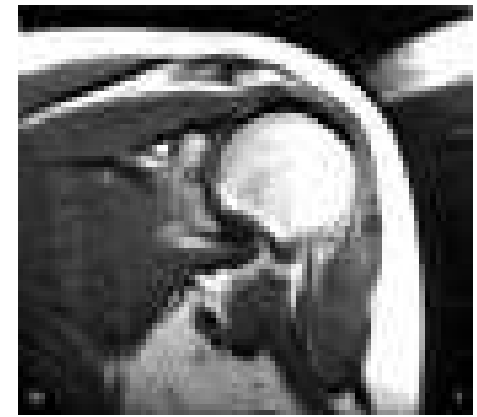

(b) ombro

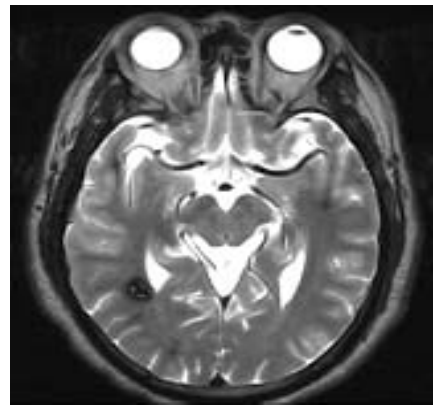

(c) crânio

Figura $1(\mathrm{a}, \mathrm{b}, \mathrm{c})$ - Alguns exemplos de exames realizados por RM

Fonte: Instituição de saúde privada 
O objetivo geral do presente trabalho concentra-se na análise das estratégias de produção identificadas nas empresas produtoras de equipamentos médicos de diagnóstico por imagem, com enfoque específico na produção de equipamentos de RM. A importância de se compreender os sistemas produtivos desses equipamentos pode ser entendida por três razões principais:

a) Pela importância de se dispor de dados e informações em países como o Brasil, que, apesar de ainda não apresentarem produção nacional, fazem uso de toda essa tecnologia e necessitam preparar recursos humanos não só para a sua própria utilização, mas também para o desenvolvimento e produção de componentes e periféricos específicos.

b) Pela importância de se avaliar qual seria a melhor estratégia a ser aplicada para implantação desse segmento de indústria em países como o Brasil;

c) Pela importância de se obter dados e informações para a área clínica que pode auxiliar, inclusive, no próprio desenvolvimento da tecnologia em si com o trabalho conjunto entre usuários e produtores.

Assim, em função das justificativas citadas e pelas aplicações clínicas possíveis, que estão sendo estudas de forma incessante, é possível identificar a relevância de se analisar e compreender o comportamento dessa indústria, cuja literatura existente, ainda hoje, apresentase muito escassa e sem trabalhos acadêmicos aprofundados sobre o assunto.

Para a realização deste estudo foi importante considerar algumas tendências existentes no que se refere a estratégias de produção. Em primeiro lugar, segundo Krajewski \& Ritzman (1996), as empresas hoje estão terceirizando suas atividades muito mais do que anteriormente, o que caracteriza uma forte tendência industrial à desverticalização. Em segundo lugar, Batalha e Silva (2001) atestam a tendência de se utilizar o conceito de cadeias de produção como ferramenta de divisão setorial dos sistemas produtivos. A utilização de parcerias para o fornecimento de insumos e componentes para a produção de equipamentos de alta tecnologia tem sido verificada, sendo possível para a empresa concentrar-se especificamente nas suas competências essenciais.

\section{CARACTERÍSTICAS GERAIS DA INDÚSTRIA DE EQUIPAMENTOS MÉDICOS}


Sob a denominação de indústria de equipamentos médico-hospitalares encontram-se inúmeros equipamentos que compõem um ramo produtivo cuja complexidade e sofisticação, como afirmam Braga e Silva (2001), assemelham-se àquelas do campo aeroespacial. Setores "conexos" tais como mecânica de precisão, eletrônica digital, informática e química provocam uma interação com a referida indústria, trazendo benefícios e avanços científicos e tecnológicos cada vez mais relevantes para a área da medicina.

Essa indústria deve ser avaliada como sendo composta por uma ampla gama de produtos e diversas bases tecnológicas, ocupando uma posição de destaque no sistema de saúde, além de uma importância crescente no complexo econômico do setor. É uma indústria que abrange um amplo espectro de empresas. Seus produtos variam da produção de simples componentes até instrumentos ou equipamentos complexos.

Para Furtado e Souza (2001), o setor de insumos e equipamentos médico-hospitalares, laboratoriais e odontológicos é caracterizado pela grande heterogeneidade tecnológica existente, o que conduz a sérias dificuldades em termos de classificação. A Associação Brasileira da Indústria de Artigos e Equipamentos Médicos, Odontológicos, Hospitalares e de Laboratórios (ABIMO), responsável por este setor no Brasil, estima que existam 11.000 famílias de produtos e classifica as empresas que respondem ao seu levantamento anual em: médico-hospitalar, radiologia, odontologia, laboratório, implantes e consumo.

A constatação de que existe certa heterogeneidade tecnológica dentro da indústria de equipamentos médicos não deve ocultar o fato de que essa indústria é, no seu conjunto, bastante dinâmica tecnologicamente. Essa característica facilita a compreensão da dificuldade dessa indústria se consolidar no cenário brasileiro e no caráter tardio vivenciado dentro do processo de industrialização nacional.

\subsection{Características da indústria de Equipamentos de Diagnóstico por Imagem}

O Brasil não apresentou, em momento algum, uma estrutura industrial que permitisse a produção de equipamentos mais complexos e caros como os de Diagnóstico por Imagem. Assim, é importante uma análise das características dessa indústria, principalmente pelo fato de que o Brasil apresenta-se como um dos maiores importadores de equipamentos deste segmento. As principais características do setor são:

\section{- Indústria baseada em tecnologia}


Assiste-se a um desenvolvimento tecnológico de grande impulsão na atualidade, sendo a modernização da tecnologia empregada um fator essencial para o desenvolvimento de qualquer atividade. Este mesmo processo é identificado no setor médico-hospitalar no qual os serviços oferecidos baseiam-se, quase que na sua totalidade, no uso e no desenvolvimento de serviços baseados em tecnologia. A dinâmica desse modelo de indústria é traduzida na diferenciação da tecnologia empregada a qual apresenta-se como base das inovações.

Além disso, segundo Pleatsikas \& Teece (2001), em indústrias de alta tecnologia, a introdução de novos produtos e a diferenciação desses produtos, associadas à inovação, são a chave do sucesso e da satisfação do usuário, sendo a competição dirigida pela inovação.

No caso dos equipamentos de diagnóstico por imagem a evolução no desenvolvimento da tecnologia empregada - uso do Raio X, do laser, de sistemas nucleares etc. - fez com que esta indústria contribuísse de forma determinante para o desenvolvimento da medicina e dos métodos de diagnóstico.

\section{- Equipamentos de Diagnóstico por Imagem como "tecnologias formadas"}

Grande parte do desenvolvimento dos equipamentos em saúde ocorre conforme a difusão da tecnologia que empregam, sendo modificados e aprimorados por seus usuários iniciais que, durante o processo de absorção no mercado, contribuem para o aprimoramento dos produtos. Por esta razão, estas tecnologias são classificadas como "tecnologias dinâmicas" (Geisler \& Heller, 1996).

No entanto, existem modelos de tecnologias que, uma vez difundidos no mercado, estão menos sujeitos a modificações, tendo havido extensa troca de informações entre produtor e usuário no período de pesquisa e desenvolvimento da tecnologia. Nesse caso, essas tecnologias são classificadas como "tecnologias formadas" (Geisler \& Heller, 1996).

As características válidas e que devem ser consideradas, no caso das tecnologias formadas, dizem respeito à complexidade sugerida pelo equipamento, sua processabilidade, a observação das possíveis conseqüências de seu uso e sua compatibilidade tecnológica (Geisler \& Heller, 1996). Os equipamentos médicos de diagnóstico por imagem estão incluídos nessa categoria, pelas especificidades apresentadas por esses equipamentos. Uma delas deve ser atribuída à questão da estreita relação existente entre a área de produção e seus usuários durante o processo de desenvolvimento de novos produtos. 


\section{- Influência das forças de demanda e oferta}

Uma característica que também deve ser identificada nesse modelo de indústria é a influência das forças de demanda e oferta. Furtado (2001) sugere atenção ao fato de que o dinamismo do mercado de equipamentos médico-hospitalares depende fortemente das forças de oferta, muito mais do que as forças de demanda, sendo capazes de constituir trajetórias industriais centradas na complexidade e na sofisticação crescente dos produtos. Furtado, apud Rieg e Alves Filho (2003), sugere, também, que se deve considerar a baixa elasticidade de substituição dos produtos dessa indústria como um fator que amplia a sua oferta, promovendo o desenvolvimento dessas soluções diferenciadas.

No caso da demanda, apesar de exercer muito menor influência do que a oferta é importante que sejam observadas algumas características que são, também, delimitadoras do comportamento dessa indústria. $\mathrm{O}$ avanço tecnológico é favorecido pela correta e constante gestão da tecnologia que, ainda que de forma indireta, auxilia nos processos de inovação, uma vez que as unidades hospitalares, que gerenciam sua tecnologia, controlam de forma mais adequada os equipamentos instalados, facilitando a identificação de possíveis melhorias em sistemas e processos.

\section{- Identificação da estratégia competitiva empregada}

Em termos de estratégia competitiva, pode-se considerar três grupos principais de indústrias, segundo classificação de Furtado (2001):

a) empresas que detêm três atributos complementares: são grandes em termos de tamanho, diversificadas quanto aos seus campos de atividade industrial e internacionalizadas em termos de estratégias de vendas;

b) empresas especializadas e internacionalizadas nas suas capacidades de reunir componentes tecnológicos e insumos dispersos e, sobretudo, nas suas estratégias de vendas;

c) empresas especializadas, focadas em mercados específicos e sem capacidade de internacionalização tão ampla quanto às dos grupos anteriores, sendo seus produtos comercializados, principalmente, por intermédio de exportações e de representantes comerciais estabelecidos.

No caso da indústria de equipamentos médicos de imagem pode-se identificar a primeira estratégia descrita como sendo a predominante nas suas empresas. Na grande maioria das vezes, estas empresas atuam com grande desenvoltura na área de equipamentos médicos 
por duas razões que se somam. Primeiro, elas possuem ativos tecnológicos específicos que podem, facilmente, ser complementados com aquisições explícitas ou formas de obtenção normalmente classificadas como associações. Segundo, o seu grau de desenvolvimento pretérito traduziu-se numa acumulação de capacidades competitivas - sobretudo em experiência produtiva e internacionalização dos seus mercados de atuação - que lhe permitiram construir, em curto período, os parâmetros necessários ao seu sucesso (Furtado, 2001).

\section{- Presença de grande concentração de mercado}

A análise da concentração desse mercado mostra que 4/5 das vendas mundiais são realizadas em apenas quatro países. Aos 45\% dos Estados Unidos agregam-se os 18\% do Japão, os 11\% da Alemanha e os 5\% da França. As soluções dominantes no campo médico reforçam-se, portanto, pela interação entre capacidade de compra, lógica competitiva que impulsiona a complexidade dos bens e serviços, vantagens financeiras acopladas e hábitos de países "abastados" (Braga e Silva, 2001).

\section{- Limitação do número de indústrias produtoras}

Pela complexidade necessária para a produção de equipamentos da indústria em questão, existe um número reduzido de empresas atuantes nesse mercado. No caso da produção de equipamentos de Ressonância Nuclear Magnética, pode-se citar como principais responsáveis pela fabricação dos equipamentos as empresas General Electric, Philips, Siemens, Toshiba, Hitashi, Elscint e Picker.

\section{SISTEMAS PRODUTIVOS IDENTIFICADOS: INTEGRAÇÃO VERTICAL VERSUS DESVERTICALIZAÇÃO}

O termo desintegração vertical ou desverticalização passou a ser utilizado para designar, segundo Amato Neto (1995), o movimento de redução do tamanho da cadeia de atividades de uma dada empresa, tanto no nível administrativo como também no nível da produção, por meio de redução ou eliminação de alguns processos, de seções produtivas ou de apoio à produção. Próximo a esse conceito encontra-se a idéia de focalização.

Essa conceituação é oposta ao termo integração vertical que tem como significado principal a idéia de que uma empresa deve produzir seus insumos e ser a responsável por 
todos os estágios do processo de produção, desde o início das atividades até as etapas finais, que incluem a própria entrega do produto final.

Quando a integração está centrada no início do processo produtivo, no que diz respeito às fontes de matéria-prima e componentes, é denominada "integração para trás" - backward. Se este envolvimento se dá no final do processo, nas atividades como a distribuição dos produtos, é conhecido como integração "para frente" - forward (Hill \& Jones, 2001).

As empresas modernas estão focalizando, cada vez mais, seus esforços nas atividades e operações que realmente possam se traduzir em vantagens competitivas para elas, especializando-se em unidades de negócios, com um número cada vez mais limitado de atividades, reduzindo o número de processos, enxugando suas estruturas e delegando a uma rede de outras empresas as funções que podem ser consideradas como complementares ou acessórias. Segundo Amato Neto (1995), o movimento em direção à essa desverticalização e terceirização parece ser um fato de dimensões internacionais. Além de buscarem novas tecnologias de produtos e de processos, assim como novas formas de organização e gestão do trabalho e da produção, as empresas, em geral, principalmente aquelas que atuam nos setores mais modernos e dinâmicos da economia mundial, estão procurando implantar e desenvolver novos padrões de relações com seus fornecedores (externos ou internos), que se refletem nas práticas de subcontratação, parcerias etc.

Assim, o objetivo maior na implementação dessa estrutura de organização industrial, na qual se destaca a importância das relações inter-empresariais, pode ser resumido na idéia de se fazer com que a grande empresa montadora possa se concentrar em apenas um conjunto de tarefas operacionais e gerenciais, constituindo, para isto, uma rede de fornecedores competentes, tanto no nível do outsourcing interno (isto é, o fato de a empresa poder contratar produtos ou serviços de outras, instaladas no próprio país de atuação) como do global sourcing (que implica um entrelaçamento mais abrangente com uma rede de fornecedores de outros países).

Nos estudos realizados foi possível identificar que as empresas pesquisadas aplicam diferentes estratégias em seus métodos produtivos. Enquanto a Siemens apresenta-se como uma empresa que tem suas atividades de produção estruturadas em um sistema de integração vertical, a Philips apresenta-se como uma empresa que tem como característica a desverticalização, com grandes parcerias estabelecidas para as suas atividades de produção. 
A questão a ser discutida baseia-se na diferença de estratégias aplicadas nas empresas. Serão avaliadas as vantagens e desvantagens de cada uma, conciliando-se o material teórico existente sobre o assunto e as características sugeridas pelas próprias empresas.

\subsection{Vantagens e desvantagens da integração vertical}

Diversas vantagens são apresentadas por Hill \& Jones (2001) para as empresas que aplicam como estratégia de produção o conceito da integração vertical. Essas mesmas vantagens foram defendidas pela Siemens para a sua aplicação nas unidades produtoras de RM.

1. A integração vertical permite à empresa a escolha sobre qual o valor agregado ela irá escolher para competir com as demais;

2. A integração vertical permite a criação de barreiras de entrada para os concorrentes, uma vez que a empresa tem controle das fontes fornecedoras de insumos críticos e pode, com isso, limitar a competição e, conseqüentemente, obter maior lucratividade;

3. A proteção da qualidade do produto é outra questão fortemente defendida para a integração vertical, pois, permite que isso seja um diferencial no seu negócio;

4. A existência de mão-de-obra qualificada na empresa é uma grande atratividade para a integração, uma vez que, isto pode ser a chave para o sucesso da empresa em um segmento específico;

5. Há também uma facilidade para investimentos em bens específicos que são criados para a realização de determinadas tarefas da produção e cujo valor investido inicialmente é significativamente reduzido ao longo do seu uso.

Assim, as vantagens apresentadas pelas empresas que são favoráveis ao sistema integrado podem ser vistas como aspectos que podem trazer lucratividade e garantia de produtos de qualidade. No entanto, existem desvantagens citadas também por Hill \& Jones (2001) que podem ser observadas na aplicação dessa estratégia e que são agravantes em sua administração. São elas:

1. Custos elevados - a integração vertical apresenta um complicador que diz respeito aos elevados custos das fontes próprias necessárias para a fabricação de seus insumos, não ocorrendo o mesmo quando do uso de fornecedores independentes; 
2. Dificuldade de mudanças tecnológicas - é extremamente difícil para uma empresa integrada alterar seus sistemas tecnológicos, caso haja mudanças tecnológicas significativas na produção e/ou nos próprios produtos perdendo com isto grau de flexibilidade;

3. Incerteza da demanda - a integração vertical é também um risco quando se analisa a instabilidade da demanda, ou seja, quando se trabalha com demandas variáveis que podem alterar todo o ritmo da produção repentinamente;

4. Dificuldade de envolvimento em novos negócios - é mais difícil que uma empresa integrada venha a competir em novos mercados no início do desenvolvimento desse novo negócio em função de sua pouca flexibilidade e das mudanças muitas vezes necessárias.

No caso da produção de RM da Siemens, a incerteza da demanda é o item que menos agride o sistema integrado verticalmente proposto e utilizado pela empresa. Deve-se lembrar que os produtos de RM são equiparados a produtos da indústria aeroespacial, existindo uma previsão bem equilibrada de suas ordens de compra. A questão do envolvimento em novos negócios também não é um fator que compromete a decisão da empresa por processos integrados, sendo este fato justificado pelo porte da mesma, o que possibilita seu envolvimento em diversos segmentos. No entanto, no que se refere aos itens custos e mudança tecnológica, não há dúvidas que são questões que podem ser vistas como desvantagens complexas e arriscadas e que são também identificadas pela Siemens como um grande "risco do negócio".

\subsection{Vantagens e desvantagens da desverticalização}

Como já dito, a empresa Philips segue uma estratégia em seu método produtivo de RM oposta àquela empregada na produção de RM pela Siemens. Aqui, todo o sistema é estruturado numa desverticalização das atividades no que diz respeito ao fornecimento de insumos para a produção (matéria-prima e componentes). Os fatores que mais contribuem para esta reestruturação das empresas, segundo Krajewski \& Ritzman (1996), podem ser identificados como sendo a competição global (através da criação de um vasto leque de fornecedores) e a tecnologia da informação (que permite, na atualidade, negociações virtuais em curtíssimos espaços de tempo). 
Neste sistema também é possível a identificação de vantagens e desvantagens na sua aplicação. A seguir, serão listadas as vantagens da desverticalização defendidas pela Philips:

1. A concentração de esforços no nas competências essenciais garante mais tempo para o desenvolvimento tecnológico, uma vez que as atividades ficam mais focadas em um único eixo;

2. Neste modelo, é indiscutível a redução geral de custos obtida - pelos custos reduzidos de transação, da manufatura focada provendo economias de escala de insumos e do baixo custo de inventário;

3. As inovações em peças e componentes fornecidos por terceiros - principalmente às relacionadas à área de informática e microeletrônica - são incorporadas pela empresa sem investimento de tempo e pessoal próprio, melhorando os sistemas de uma forma indireta;

4. A divisão setorial das atividades conjugadas entre as empresas cria, efetivamente, um sistema no qual as empresas fornecedoras são co-responsáveis pelo produto final, o que aumenta a responsabilidade das mesmas e melhora o funcionamento do sistema como um todo;

5. A existência de maior possibilidade de criação de bens e serviços customizados e soluções integradas para toda a cadeia de suprimentos auxilia na criação de produtos adequados à solicitação do fornecedor do produto final, além da facilidade de mudança rápida quando há mudança da demanda.

Assim, as vantagens apresentadas são amplamente exploradas pela Philips, como conseqüência de seguir a estratégia de desverticalização. E quais seriam as desvantagens apontadas para este modelo de sistema produtivo?

1. O maior problema a ser administrado por empresas que desverticalizaram seus processos de produção pode ser entendido como os custos burocráticos necessários para sua estrutura que, muitas vezes, excedem o valor criado pela implantação dessa estratégia. Esses custos podem ser identificados por dois motivos - pelo número de negócios da empresa e pela necessidade de coordenação entre os agentes e os negócios; 
2. Outro fator a ser considerado sugere o excesso de dependência criada da empresa com os fornecedores externos que devem ser de total confiabilidade em termos de prazos, qualidade etc.

Deve-se observar que uma grande quantidade de empresas está baseando suas atividades em estruturas desverticalizadas, se não no todo, pelo menos em partes do processo produtivo (Krajewski \& Ritzman, 1996).

\section{INDÚSTRIA DE RM: ESTRATÉGIAS E PROCESSOS PRODUTIVOS IDENTIFICADOS NAS EMPRESAS ESTUDADAS}

A abordagem do trabalho teve como foco principal, especificamente no que diz respeito aos estudos de casos realizados, identificar as características da indústria de RM das empresas estudadas. Como dito anteriormente, pretendia-se analisar os sistemas de produção aplicados em empresas que produzem estes equipamentos, para que fosse possível a realização de um diagnóstico mais preciso em termos de estratégias e processos produtivos.

As visitas técnicas realizadas nas empresas tiveram, como base de coleta de informações, a observação e o uso de um roteiro de entrevistas que cobria os tópicos: Panorama Geral e Contextual; Avaliação Produtiva; Processo de Produção; Unidades Operacionais e Pesquisa e Inovação, totalizando 50 (cinqüenta) questões.

Foi possível, durante as visitas realizadas, identificar uma grande diferença no que se refere aos métodos aplicados na produção de RM em cada empresa, apesar de similaridades em certos aspectos.

A Siemens apresenta-se como uma empresa que tem sua produção voltada para uma "não terceirização" das atividades, ao contrário da Philips que tem suas atividades distribuídas por diversas empresas fornecedoras, caracterizando a existência de uma cadeia produtiva.

Serão analisadas a seguir, as características de cada empresa em termos de sistemas produtivos. Cabe ressaltar que, em função de suas diferentes estratégias produtivas, as empresas disponibilizaram informações não homogêneas sobre o conjunto de áreas e variáveis pesquisadas.

\subsection{Produção de RM na Siemens Medical}


Com mais de 150 anos de atividades, a Siemens é uma das maiores empresas produtoras de eletroeletrônicos no mundo. Atualmente, tem concentrado as atividades no campo do e-business por meio de soluções em seis segmentos de negócios: Informação e Comunicação; Automação e Controle; Energia; Transporte; Iluminação e Área Médica.

A Siemens Medical, por sua vez, é uma empresa produtora de equipamentos para a saúde, tendo um grande foco em equipamentos de diagnóstico por imagem. Sua unidade de produção de RM está sediada em Earlegen, na Alemanha, onde foram realizadas as visitas técnicas. A unidade de RM situa-se em uma região de concentração de atividades médicas lideradas pela empresa.

O estudo realizado em sua unidade de RM permitiu a realização de uma comparação entre dois métodos distintos aplicados em processos produtivos para um mesmo produto. A maior diferença identificada entre as empresas estudadas refere-se à questão de terceirizar ou não as atividades da produção - ser ou não integrada verticalmente.

Apesar da tendência existente a uma organização de processos produtivos em formato de cadeias, sendo os sistemas focados predominantemente no produto final, foi possível identificar uma organização centrada no processo produtivo em si quando se avalia a Siemens. Com uma produção de mais de $80 \%$ de suas atividades realizadas internamente, são identificadas questões distintas no que se refere à sua preocupação da empresa em termos produtivos. A justificativa para que o foco da preocupação seja também o seu processo produtivo, e não só o seu produto final, deve-se aos fatores citados a seguir.

1) A empresa ter sempre trabalhado observando as estratégias operacionais aplicadas internacionalmente e trazendo para análise interna a aplicação destas estratégias em seus processos produtivos, ou seja, realizando uma comparação das operações aplicadas em outras empresas com seus processos;

2) Essas comparações auxiliaram na identificação de questões críticas, com a identificação das operações que são afetadas por questões relacionadas à globalização, como a difusão do conhecimento e da informação;

3) Esses aspectos trouxeram uma grande preocupação com o gerenciamento do risco dos negócios da empresa e uma filosofia da empresa de desenhar seus modelos estruturais, inclusive seus modelos produtivos para que fosse possível gerenciar, da melhor maneira, a própria questão dos riscos operacionais. 
Os fatores citados ilustram a filosofia aplicada na empresa quanto à preocupação com suas estratégias operacionais. Para melhor compreensão da estratégia aplicada pela Siemens é importante observar alguns aspectos.

Existem na empresa nove departamentos corporativos que atuam, especificamente, nas questões de P\&D. Todos estes departamentos avaliam as estruturas aplicadas nos negócios na intenção de aproximar ao máximo as atividades de produção das atividades de pesquisa, permitindo que todos os "negócios" da empresa apresentem uma identificação própria de produto ou processo produtivo aplicado em cada unidade de produção.

Dentro dessa filosofia, a produção de RM sofreu uma grande remodelação. A nova planta da empresa trouxe grandes benefícios para a produção em si, otimizando processos e auxiliando no desenvolvimento de pesquisas focadas em melhorias do equipamento de RM. Estas melhorias trouxeram para a empresa um reconhecimento destacado em termos de tecnologia de ponta para equipamentos de diagnóstico de imagem.

Pela grande distribuição de suas plantas produtivas em diversos países, é possível para a empresa decidir o melhor local para a produção de cada produto e permitir uma soberania de suas empresas em decisões estratégicas de produção. A ênfase da empresa em desenvolver seus processos produtivos de forma tão interna e própria traz vantagens competitivas que resultam diretamente dos processos de manufatura:

a) O aumento nos níveis de produção com redução de custos;

b) Os altos índices de inovação nas tecnologias aplicadas nos produtos com diminuição do tempo necessário ao processo de inovação;

c) A expansão em novos mercados geográficos para o crescimento da estabilidade da base tecnológica dos produtos desenvolvidos e

d) A criação de uma nova cultura corporativa na qual é focada a satisfação do cliente, a remoção de barreiras organizacionais para o crescimento do grau de liberdade dos próprios empregados, o incentivo da responsabilidade e a capacidade de fornecer treinamento e motivação.

A produção da RM segue uma filosofia que é aplicada em todas as unidades. A empresa identifica, como sendo o melhor sistema de produção, aquele que não é caracterizado pela terceirização de atividades. Considerando-se que os componentes básicos para a produção de RM são componentes eletrônicos e a empresa apresenta uma grande produção 
nessa linha de produtos, a decisão da empresa foi de não terceirizar. Com a produção desses componentes, considera-se que, mais de $70 \%$ do sistema (seja de materiais, componentes, peças e/ou acessórios) é produzido pela Siemens, sendo o restante relacionado, principalmente, à área de informática.

Uma filosofia aplicada em todos os processos de produção de equipamentos médicos da Siemens é que a empresa seja detentora de todo o conhecimento de fabricação dos principais componentes, ou seja, daqueles que são chave do sistema. Assim, segundo a empresa, um dos principais cuidados que se deve ter com a terceirização é saber exatamente o que pode e o que deve ser terceirizado, para que não seja externalizado o conhecimento-chave da produção.

Considerando-se que a característica descrita acima acelera o processo e cria uma grande independência da empresa, é empregada na produção a filosofia just-in-time, especificamente com utilização do kanban de processo.

Uma outra característica do sistema produtivo da empresa é não haver estoque de unidades de RM para venda. O equipamento só é produzido após o fechamento da compra por um cliente. A empresa considera uma grande vantagem competitiva este aspecto, ainda que o comprador tenha que esperar mais tempo pela aquisição do que esperaria em outras empresas. Ainda assim, a empresa chega a produzir mil unidades de RM por ano.

A maior mudança introduzida pela empresa nos últimos dez anos, no que se refere aos sistemas de RM, diz respeito à oferta de sistemas completos e totalmente integrados aos clientes. Isto considera o fornecimento, não só do equipamento em si, mas de toda a estrutura necessária e as soluções de software e de avaliações remotas (à distância) adequadas aos sistemas. O desenvolvimento desta plataforma teve a duração de aproximadamente três anos, tendo sido possível apenas por ser uma empresa de grande porte, uma vez que, empregava centenas de pessoas como médicos, engenheiros, físicos, matemáticos etc., ou seja, uma estrutura que uma empresa de pequeno ou médio porte não conseguiria sustentar.

\subsection{Produção de RM na Philips Medical Systems}

A Royal Philips Electronics também é um dos maiores fabricantes mundiais de produtos eletroeletrônicos, estando presente em mais de 60 países, atuando nas áreas de: 
Iluminação; Componentes Eletroeletrônicos; Semicondutores; Serviços de Informática e Sistemas Médicos.

A Philips Medical Systems é o segmento produtor de equipamentos médicos, entre eles todos os modelos de equipamentos de diagnóstico por imagem. Sua empresa produtora de RM está localizada em Eindhoven, na Holanda, local do segundo conjunto de visitas técnicas.

No caso da Philips pode-se identificar um processo que caminha em um sentido oposto ao descrito anteriormente na Siemens, sendo possível a identificação de uma cadeia produtiva do tipo supply chain. O desenho dessa cadeia produtiva pode ser considerado como o apresentado na Figura 2 que mostra a estrutura das atividades que a compõem.

Estas atividades atuam de forma integrada, com grande participação de fornecedores externos, principalmente na atividade de fornecimento de componentes. É possível verificar claramente uma desverticalização das atividades desenvolvidas, caracterizando a existência de uma cadeia produtiva.

A RM na Philips encontra-se em plena reestruturação na sua linha de produção, no que se refere à área de componentes eletrônicos, para poder, cada vez mais, otimizar os processos produtivos e se organizar junto aos fornecedores.

A filosofia aplicada é a de que o que funciona perfeitamente em uma linha de produção e o que faz com que seja bem sucedida a organização industrial é possuir uma logística bem organizada com todos os fornecedores que trabalham com a empresa.

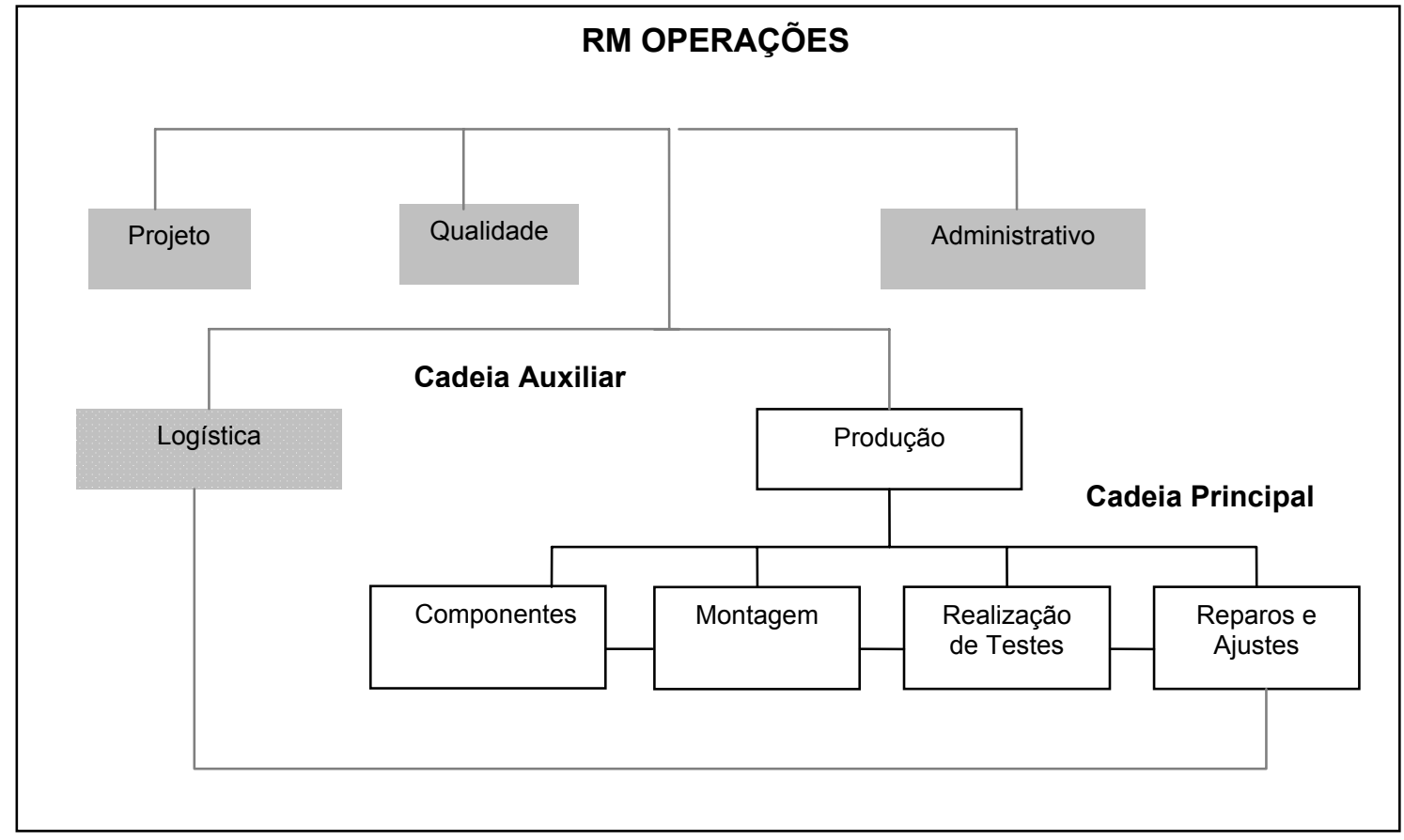

Revista Produção Online, Florianópolis, v.7, n.7,p.32, dez./abr., 2007 
Figura 2 - Desenho da cadeia produtiva com as atividades da cadeia principal e da auxiliar

Deve-se atentar para o fato de que, por trabalharem com produtos que são caracterizados por não serem bens de consumo e apresentarem uma produção limitada, a ocorrência de uma cadeia produtiva baseada em fornecedores externos é identificada somente nas atividades da cadeia principal.

Apesar do emprego de técnicas de kanban já em diversos setores, a intenção é estender essa filosofia a todos os processos de produção. A utilização de kanban de fornecedor em todos os departamentos é a proposta da empresa para que eles consigam manter (e atingir em outros departamentos) as vantagens justificadas pela aplicação do sistema e apresentadas a seguir:

1. Flexibilidade das atividades de reposição de componentes e peças, automaticamente, não sendo necessária a solicitação de compra / entrega por parte da Philips - o fornecedor vem à fábrica a cada duas semanas avaliar e repor, posteriormente, o material necessário;

2. Evitar a ocorrência de estoques de componentes e peças;

3. Permitir a produção de diversas unidades de RM simultaneamente, uma vez que, ao contrário da empresa analisada anteriormente, a Philips possui unidades pré-fabricadas à espera de um comprador.

Os principais dados sobre a produção de RM pela Philips podem ser identificados como os seguintes:

a) Tempo estimado para a produção de uma $\mathrm{RM}=15$ dias

b) Tempo estimado para empacotamento e despacho $=10$ dias

c) Tempo estimado para testes do sistema: de rede $=3$ dias e total $=5$ dias

d) Mudanças estimadas por ano no produto $=500$

e) Tempo aproximado de implementação das mudanças $=60$ dias

f) As maiores características da RM são: apresenta um peso aproximado de 10 toneladas, pode ser transportada em caminhão de grande porte e possui 10 anos de garantia após sua implantação no cliente. 
A maior mudança identificada pela empresa refere-se ao surgimento de magnetos compactos desde 1996. Esta evolução trouxe maior flexibilidade aos sistemas e auxilia em maior divulgação da tecnologia. Outra questão citada refere-se às constantes evoluções dos dispositivos que reduzem, cada vez mais, o tempo empregado nos exames.

A Philips aplica hoje boa parte do tempo em estudos referentes à evolução dos sistemas abertos. Um dos motivos é a facilidade com que essas unidades avaliam extremidades com maior conforto aos pacientes atendendo de forma melhor crianças, idosos, obesos e pessoas com claustrofobia.

\section{CONSIDERAÇÕES}

O presente artigo teve como finalidade apresentar alguns dados relevantes sobre as estratégias produtivas aplicadas na produção de equipamentos de imagem, tendo como foco principal a produção de equipamentos de ressonância magnética.

Com as informações obtidas durante as visitas realizadas nas empresas selecionadas Siemens Medical e Philips Medical Systems - foi possível identificar formas distintas de estratégias produtivas aplicadas em empresas produtoras de equipamentos de $\mathrm{RM}$ - empresas integradas verticalmente e desverticalizadas com, inclusive, o surgimento de cadeias produtivas.

Pode-se considerar como informações gerais relevantes os seguintes itens:

- A indústria de equipamentos de imagem, no que se refere aos equipamentos de RM, é extremamente complexa, pois trabalha com equipamentos de alta base tecnológica e depende de freqüentes inovações e melhorias;

- As empresas produtoras são empresas de grande porte que, normalmente, atuam em diversos segmentos, inclusive nos não relacionados à área de saúde;

- $\quad \mathrm{O}$ mercado produtor de equipamentos de RM apresenta um reduzido número de empresas concorrentes;

- As empresas desverticalizadas reforçam a idéia de que a organização em formato de cadeia produtiva é importante para o desenvolvimento e a evolução contínua dos produtos; 
- A influência de usuários no desenvolvimento de novos projetos de produtos é inquestionável, tendo sido identificada esta relação ao longo de todo o levantamento realizado nas empresas.

Analisando-se o Quadro 1 descrito a seguir, que resume as principais vantagens e desvantagens das duas estratégias discutidas ao longo do texto, é possível identificar que a organização em um sistema produtivo desverticalizado pode apresentar-se como sendo mais adequada para a implantação de indústrias desse perfil em países como o Brasil, tendo como principal vantagem a maior flexibilidade gerada pela organização desverticalizada. Em países que apresentam maior instabilidade financeira é de extrema relevância a possibilidade de novos negócios ou de mudanças rápidas em processos produtivos para uma nova adequação da empresa ao mercado.

Um dos principais elementos que deve ser destacado pela desverticalização da empresa refere-se à questão da flexibilidade de mudança de nichos de mercado. Empresas de grande porte costumam atuar em diversos segmentos, muitas vezes absolutamente distintos, podendo a empresa que apresenta um modelo de estrutura integrada ter dificuldades de ingressar nesses novos mercados.

É importante considerar que uma grande vantagem da empresa desverticalizada é a possibilidade de liberação de recursos como:

- Patrimônio: menor necessidade de área física uma vez que a produção é pulverizada;

- Infra-estrutura: diretamente relacionada à redução de recursos de patrimônio e, principalmente, à redução de estoque;

Quadro 1 - Vantagens e desvantagens das estratégias apresentadas nos sistemas produtivos

\begin{tabular}{|c|c|c|}
\hline & VANTAGENS & DESVANTAGENS \\
\hline $\begin{array}{c}\text { INTEGRAÇÃO } \\
\text { VERTICAL }\end{array}$ & $\begin{array}{l}\text { Permite a escolha do valor } \\
\text { agregado ao produto } \\
\text {. Permite a criação de barreiras } \\
\text { de entrada para os concorrentes } \\
\text {. Amplia a proteção da } \\
\text { qualidade do produto }\end{array}$ & $\begin{array}{l}\text {. Eleva os custos } \\
\text {. Dificulta as mudanças } \\
\text { tecnológicas } \\
\text {. Trabalha com uma grande } \\
\text { incerteza da demanda } \\
\text {. Dificulta a entrada da }\end{array}$ \\
\hline
\end{tabular}


ISSN 1676 - 1901 / Vol. 7/ Num.1/ abril/2007

\begin{tabular}{|c|c|c|}
\hline & $\begin{array}{l}\text {. Permite a formação de mão- } \\
\text { de-obra especializada } \\
\text {. Facilita o investimento em } \\
\text { bens específicos para as tarefas } \\
\text { de produção }\end{array}$ & $\begin{array}{l}\text { empresa em novos negócios } \\
\text {. Necessita de uma grande } \\
\text { estrutura e conhecimento em } \\
\text { áreas diversas }\end{array}$ \\
\hline DESVERTICALIZAÇÃO & $\begin{array}{l}\text {. Apresenta maior flexibilidade } \\
\text { para mudanças nas áreas de } \\
\text { atividades } \\
\text {. Facilita o desenvolvimento } \\
\text { tecnológico pela concentração } \\
\text { no core business } \\
\text {. Reduz os custos gerais } \\
\text {. Incorpora inovações de forma } \\
\text { indireta, trazidas pelos } \\
\text { fornecedores que integram a } \\
\text { cadeia produtiva } \\
\text {. Cria um sistema de co- } \\
\text { responsabilidade com esses } \\
\text { fornecedores } \\
\text { Permite maior criação de } \\
\text { produtos customizados e } \\
\text { adequados à solicitação do } \\
\text { consumidor final } \\
\text {. Permite a organização de uma } \\
\text { estrutura em cadeia produtiva } \\
\text {. Apresenta maior flexibilidade } \\
\text { de reposição (aumento / } \\
\text { diminuição) nos estoques }\end{array}$ & $\begin{array}{l}\text {. Eleva os custos burocráticos } \\
\text { pelo número de negócios da } \\
\text { empresa e pela necessidade de } \\
\text { coordenação entre os agentes } \\
\text { do negócio } \\
\text {. Cria um excesso de } \\
\text { dependência dos fornecedores } \\
\text { externos }\end{array}$ \\
\hline
\end{tabular}

- Mão-de-obra: grande parte da mão-de-obra é responsabilidade das empresas parceiras e coligadas; 
- Competências especializadas: pode ser dividida com as empresas fornecedoras.

Além disso, a existência de cadeias produtivas, geradas a partir de novos conceitos das empresas de haver uma preocupação central apenas com o seu core business, pode ser interpretada como sendo uma tendência à eliminação de esforços em atividades complementares para uma concentração em sua "atividade fim".

Esta atividade fim deve ser entendida, não só como a produção de equipamentos de RM, mas, também, como o desenvolvimento de unidades cada vez mais aptas a fornecerem maior precisão diagnóstica com qualidade e, principalmente, maior expansão das suas aplicações em saúde.

Desta forma, foram resumidas nesse artigo as informações mais relevantes obtidas sobre as vantagens e desvantagens de cada sistema identificado, na tentativa não só de se avaliar qual seria a melhor opção para uma implantação da indústria de RM em países como o Brasil como também de se aprofundar o conhecimento específico de aspectos operacionais da produção de equipamentos médico-hospitalares.

O tema pesquisado surgiu da identificação da falta de informações de qualidade existente para o desenvolvimento do setor industrial e até mesmo para auxiliar o setor acadêmico, uma vez que, a própria área de Engenharia de Produção, apesar de apresentar diversos estudos relacionados ao tema "processos produtivos", não apresenta pesquisas e trabalhos que se relacionem à área de Diagnóstico por Imagem.

\section{REFERÊNCIAS}

AMATO NETO, J. Reestruturação Industrial, Terceirização e Redes de Subcontratação. Revista de Administração de Empresas, São Paulo, v. 35, n. 2, março/abril 1995.

BATALHA, M. O. e Silva, A. L. Gerenciamento de Sistemas Agroindustriais: Definições e Correntes Metodológicas. In Mário Otávio Batalha (coord.), Gestão Agroindustrial, São Paulo: Editora Atlas, 2001.

BRAGA, J. C. S. e SILVA, P. L. B. A Mercantilização Admissível e as Políticas Públicas Inadiáveis: Estrutura e Dinâmica do Setor Saúde no Brasil. In Negri, B. e Di Giovanni, G. (coord.), Brasil Radiografia da Saúde, Campinas: Editora do Instituto de Economia da Unicamp, 2001. 
FURTADO, J. A Indústria de Equipamentos Médico-Hospitalares: Elementos para uma Caracterização da sua Dimensão Internacional. In Negri, B. e Di Giovanni, G. (coord.), Brasil Radiografia da Saúde, Campinas: Editora do Instituto de Economia da Unicamp, 2001.

FURTADO, J. e SOUZA, J. H. Evolução do Setor de Insumos e Equipamentos MédicoHospitalares, laboratoriais e odontológicos no Brasil: a década de 90. In Negri, B. e Di Giovanni, G. (coord.), Brasil Radiografia da Saúde, Campinas: Editora do Instituto de Economia da Unicamp, 2001.

GE Sistemas Médicos. O que é Ressonância Magnética? São Paulo. Disponível em $<$ http://www.gemedicalsystems.com/lapt/rad/mri/education/patient/what.html $>$. Acesso em 03/11/2003.

GEISLER, E. \& HELLER, O. Managing Technology in Healthcare. USA: Kluwer Academic Publishers, 1996.

HILL, C. W. L. \& JONES, G. R. Strategic Management Theory - An Integrated Approach. Annual Update. Means Business, Inc., 2001

KRAJEWSKI, L. J. \& RITZMAN, L. P. Operations Management: Strategy and Analysis. USA: Addison-Wesley Publishing Company, Inc., 1996.

PLEATSIKAS, C. \& TEECE, D. The Analysis of Market Definition and Market Power in tha Context of Rapid Innovation. International Journal of Industrial Organization, USA: Elsevier Science B.V., 2001.

RIEG, D. L. e ALVES FILHO, A. G. Esforço Tecnológico e Desempenho Inovador das Empresas do Setor Médico-Hospitalar Localizadas em São Carlos. Gestão e Produção. São Paulo: Universidade Federal de São Carlos, v. 10, n. 3, Dezembro / 2003.

Artigo recebido em 02/2006 e aprovado para a publicação em 04/2007 